\title{
Semaphorin 3F Confines Ventral Tangential Migration of Lateral Olfactory Tract Neurons onto the Telencephalon Surface
}

\author{
Keisuke Ito, ${ }^{1}$ Takahiko Kawasaki, ${ }^{1}$ Seiji Takashima, ${ }^{2}$ Ikuo Matsuda, ${ }^{3}$ Atsu Aiba, ${ }^{3}$ and Tatsumi Hirata ${ }^{1}$ \\ ${ }^{1}$ Division of Brain Function, National Institute of Genetics, Graduate University for Advanced Studies (Sokendai), Yata 1111, Mishima 411-8540, Japan, \\ ${ }^{2}$ Health Care Center, Osaka University, Suita, Osaka 565-0871, Japan, and ${ }^{3}$ Division of Molecular Genetics, Kobe University Graduate School of Medicine, \\ Kobe 650-0017, Japan
}

\begin{abstract}
Ventral tangential migration of neurons is the most prominent mode of neuronal translocation during earliest neurogenesis in the mouse telencephalon. A typical example of the neurons that adopt this migration mode is guidepost neurons in the lateral olfactory tract designated as lot cells. These neurons are generated from the neocortical neuroepithelium and migrate tangentially down to the ventral edge of the neocortex abutting the ganglionic eminence, on which the future lateral olfactory tract develops. We show here that this migration stream is repelled by a secreted axon guidance molecule, semaphorin $3 \mathrm{~F}$ through interaction with its specific receptor, neuropilin-2. Accordingly, in mutant mice for semaphorin $3 F$ or neuropilin-2, lot cells ectopically penetrated into the deep brain domain, which normally expresses semaphorin $3 \mathrm{~F}$. These results reveal that semaphorin $3 \mathrm{~F}$ is an important regulator of the ventral tangential migration stream, confining the migrating neurons on the telencephalon surface by repelling from the deeper domain.
\end{abstract}

Key words: neuronal migration; semaphorin 3F; neuropilin-2; lateral olfactory tract; lot cell; repulsive guidance

\section{Introduction}

In the developing telencephalon, neurons generated in the innermost layer migrate thorough two distinct streams, radial and tangential (Nadarajah and Parnavelas, 2002; Marin and Rubenstein, 2003). In the radial migration, neurons vertically translocate to the outer surface, whereas in the tangential migration, neurons travel parallel to the surface. The radial migration is the major strategy for constructing the six-layer cerebral cortex, and thus has been well studied in many laboratories. It is only in recent years that the tangential migration has been recognized as a critical migratory mode to distribute various neurons to their functionally appropriate areas. A notable example is the delivery of GABAergic interneurons. These neurons differentiate from the ganglionic eminence (GE), the ventral subcortical area, and translocate to the neocortex via the "dorsal tangential migration" to implement the inhibitory circuits indispensable for cortical function (Anderson et al., 1997; Tamamaki et al., 1997).

There are also neurons that make the "ventral tangential migration" in the opposite direction (see Fig. 1A). Previously, we

Received Aug. 27, 2007; revised Feb. 21, 2008; accepted March 17, 2008

This work was supported by grants from the Ministry of Education, Sports, Science and Technology of Japan and Japan Science and Technology Corporation. K.I. is supported by the Japan Society for the Promotion of Science Fellowship. We thank Drs. Hajime Fujisawa and Fumikazu Suto for Sema3A-E cDNAs, Dr. Marc Tessier-Lavigne for Sema3F cDNA, and Dr. Tadashi Nomura for critical reading of this manuscript.

Correspondence should be addressed to Dr. Tatsumi Hirata, Division of Brain Function, National Institute of Genetics, 1111 Yata, Mishima 411-8540, Japan. E-mail: tathirat@lab.nig.ac.jp.

I. Matsuda's present address: Department of Surgical Pathology, Hyogo College of Medicine, Nishinomiya, Hyogo 663-8501, Japan.

DOI:10.1523/JNEUROSCI.0372-08.2008

Copyright $\odot 2008$ Society for Neuroscience $\quad$ 0270-6474/08/284414-09\$15.00/0 discovered a neuronal population immunoreactive to monoclonal antibody (mAb) lot1 and designated it "lot cell" (Sato et al., 1998). At the earliest stage of neurogenesis, the lot cells differentiate from the whole neocortical area, and migrate on the brain surface ventrally and tangentially (Tomioka et al., 2000). This ventral tangential migration stream abruptly terminates at the boundary between the neocortex and the GE (Hirata et al., 2002), on which the accumulated neurons line up as a horizontal cellular array and pave the way for the projecting olfactory bulb axons to construct the lateral olfactory tract (LOT) (Sato et al., 1998). Although this migration mode had been somehow overlooked until our finding, actually, this stream is most prevalent in the early stage of the telencephalon (Kawasaki et al., 2006), and inevitably has a large impact on the subsequent processes in the construction of the functional brain.

Two types of guidance mechanisms have been proposed for the ventral tangential migration (Kawasaki et al., 2006). One is the graded signal along the dorsoventral axis, which directs neuronal migration ventrally. Netrin-1, an axon guidance molecule expressed in the ventral telencephalon, could partly contribute to this signal, locally attracting the neurons around the neocortex-GE boundary. The other critical signal is repulsion from the GE, which probably underlies the termination of the ventral migration and alignment of the neurons on the interface between the neocortex and the GE. Yet, the molecular basis for this repulsion remains completely unknown.

Here, we report an additional mechanism that controls the ventral tangential migration. Semaphorin $3 F$ (Sema3F) is an axon guidance molecule expressed in the developing GE. We found 
that this protein repels the ventral tangential migration through its specific receptor, neuropilin-2 (Nrp2). In Nrp2 and Sema3F knock-out mice, lot cells were ectopically dispersed into the deep layers toward the GE. These results postulate a new physiological function of Sema3F/Nrp2 signaling in excluding the tangentially migrating neurons from the GE and confining them on the brain surface.

\section{Materials and Methods}

Mice. Staged pregnant ICR wild-type mice were purchased from Japan SLC (Shizuoka, Japan). Nrp2 knock-out mice (Takashima et al., 2002) were maintained in the ICR background in the animal facility of the National Institute of Genetics. Sema3F knock-out mice were generated by gene targeting in 129/Ola embryonic stem cells (I. Matsuda, M. Fukada, H. Nakao, K. Nakao, H. Matsumoto, K. Mori, M. Watanabe, and A. Aiba, unpublished observations). The targeting vector was constructed so that the lac $Z$ gene was knocked into the Sema3F exon 3 in frame (Matsuda, Fukada, Nakao, Nakao, Matsumoto, Mori, Watanabe, and Aiba, unpublished observations). Northern blot analysis and in situ hybridization have confirmed the complete loss of Sema3F mRNA in the knock-out mice (Matsuda, Fukada, Nakao, Nakao, Matsumoto, Mori, Watanabe, and Aiba, unpublished observations). The Sema3F knock-out mice were initially established in hybrid background of 129/Ola and C57BL/ 6 and then backcrossed to C57BL/6 for four generations. For this study, the mice (C57BL/6, N:4) were crossed into the ICR background for three to four generations. Nrp2 and Sema3F mutant embryos were obtained by intercrosses of the heterozygous mutant parents. The day on which a vaginal plug was detected was designated as embryonic day 0.5 (E0.5). All experimental protocols were approved by the Animal Committee of the National Institute of Genetics.

Culture. The methods of telencephalic slice culture were described previously (Kawasaki et al., 2006). Briefly, $\sim 1.5$-mm-wide slices were dissected along the dorsoventral axis from the E10.5 telencephalons (Fig. $1 B)$. The slices were cultured with the ventricular side down on a collagen-coated membrane filter (Corning, Action, MA) for 3-4 d, after the injection of 1,1-dioctadecyl-3,3,3',3'-tetrametylindocarbacyanine perchlorate (DiI; Invitrogen, Eugene, OR) into a small area of the dorsal neocortex. Semaphorin cDNA expression constructs mixed with a green fluorescent protein (GFP) expression vector as a transfection control, were introduced into human embryonic kidney 293T (HEK293T) cells using transfection reagent Effectene (Qiagen, Hilden, Germany). Cell aggregates were prepared by hanging drop culture (Fan et al., 1995) and placed on the lateral side of telencephalic slices.

Histochemistry. The method used for immunostaining of telencephalons with monoclonal antibody (mAb) lot1 was described previously (Sato et al., 1998). Immunostaining of cultured cortical neurons was performed as described previously (Tomioka et al., 2000). Goat antiNrp2 antibody (R\&D Systems, Minneapolis, MN) and rabbit anti- $\beta$ galactosidase (Invitrogen) were used in the study. For in situ hybridization, digoxigenin (DIG)-labeled RNA probes were transcribed from a Sema3F cDNA fragment subcloned in pBluescript (Stratagene, La Jolla, CA) with DIG RNA labeling kit (Roche Diagnostics, Mannheim, Germany). The hybridization was performed as described previously (Schaeren-Wiemers and Gerfin-Moser, 1993)

Cell counting and statistical analysis. To analyze the distribution of DiI-labeled cells, cultured telencephalic slices were fixed with $4 \%$ paraformaldehyde in PBS, and fluorescent images were immediately taken with a cooled CCD camera (CoolSnap; Photometrics, Drive Tucson, AZ) under a fluorescent microscope (Axioplan2; Carl Zeiss, Jena, Germany). Each image of a slice was intersected into eight sections as detailed in the figure legend, using the Adobe Illustrator software (Adobe Systems, San Jose, CA). The number of DiI-labeled cells in each section was counted on a computer screen and plotted on a radar graph. In some analyses, the total numbers of cells in the distal and proximal areas were counted and compared statistically by the Student's $t$ test. To evaluate repulsive effect on lot cells, cultured telencephalic slices were immunolabeled with $\mathrm{mAb}$ lot1. The number of lot cells in contact with the cell aggregates was counted under a fluorescent microscope (Axioplan2; Carl Zeiss) and used for the statistical analysis by the Student's $t$ test.

For quantification of ectopically located lot cells, 15 - serial $25-\mu \mathrm{m}$ thick sections were prepared from the middle level of the telencephalon within the range of $200-600 \mu \mathrm{m}$ caudal to the base of the olfactory bulb. In each hemisphere section, the total number of lot cells and the number of these cells dispersed from the brain surface over the medial deep domain were counted under a fluorescent microscope (Axioplan2; Carl Zeiss). The average number of these cells per each hemisphere section was calculated from the pooled data of the indicated numbers of embryos and analyzed statistically by the Student's $t$ test.

\section{Results}

\section{Sema3F repels neurons in ventral tangential migration}

The massive ventral tangential migration of neurons is readily reproducible in telencephalic slice culture (Kawasaki et al., 2006). When a small number of ventricular cells in the E10.5 dorsal neocortex were labeled with fluorescent dye DiI, most of the labeled cells that escaped from the ventricular zone were found to have migrated ventrally during subsequent cultures for 3-4 d (Fig. $1 A-C$ ). These putative neurons made a characteristic rightangle turn at the ventral edge of the neocortex bordering the GE, and constituted a horizontal cellular array along this boundary as do lot cells in vivo (Fig. 1C). Our previous study showed that this tangential migration stream indeed contains future lot cells and probably other uncharacterized constituents (Tomioka et al., 2000; Kawasaki et al., 2006).

Semaphorins are a large conserved family of proteins involved in various developmental processes (Raper, 2000; Pasterkamp and Kolodkin, 2003; Kruger et al., 2005). Among them, class 3 semaphorins are secreted proteins that repel various types of axons and cell migrations (Luo et al., 1993; Kitsukawa et al., 1997; Giger et al., 1998; Marin et al., 2001), and consist of several different members such as Sema3A through 3F. We found that Sema3F (Roche et al., 1996; Sekido et al., 1996; Xiang et al., 1996) had a repulsive effect on the ventral tangential migration. When an aggregate of HEK cells expressing Sema3F was placed on one side of the telencephalic slice, many DiI-labeled cells deviated from the cell aggregate toward the opposite direction (Fig. $2 B$ ), whereas the mock control cells that were transfected only with the GFP expression vector did not affect the migration (Fig. $2 A$ ). The resultant distribution of DiI-labeled cells showed a clear shift of the cell migration toward the area distal to the source of Sema3F (Fig. 2C-E). The proportion of the cells that migrated in the area proximal to the Sema3F-expressing cell aggregates was $17.4 \pm$ $2.7 \%(n=53)$, which was significantly lower than $42.4 \pm 3.5 \%$ $(n=69)$ cultured with mock transfectants $(p<0.001$ by Student's $t$ test). We also tested the effects of cDNA constructs for other class 3 semaphorin members (Sema3A, B, C, D, and E), but none of them exhibited a significant effect on the ventral tangential migration (data not shown).

To address whether Sema3F indeed repelled lot cells in the ventral tangential migration stream, aggregates of the transfectants were combined with the caudal end of telencephalic slices, and cultured without DiI labeling. Subsequently, the slices were immunostained with mAb lot. Because immunoreactivity to $\mathrm{mAb}$ lot 1 develops relatively late during differentiation of lot cells (Tomioka et al., 2000), we barely detected lot1-positive cells in the actual migratory stage, but readily marked an array of postmigratory lot cells lining up on the neocortex-GE boundary. In the slices cultured with mock-transfected cell aggregates, many lot cells on the combination end contacted the cell aggregates; some even were accumulated along the edge of the aggregate (Fig. $2 \mathrm{~F}$ ). In contrast, very few lot cells were in contact with Sema3F- 
expressing cell aggregates, leaving a lot cellsparse area around the aggregate (Fig. 2G). The average number of lot cells in contact with Sema3F-expressing cells $(16.9 \pm 2.7$, $n=30)$ was significantly lower than that with mock transfectants $(42.0 \pm 3.0, n=$ $26)$ by Student's $t$ test $(p<0.001)$.

\section{Neuropilin-2 mediates the repulsion by Sema3F}

Class 3 semaphorins require neuropilins, type 1 transmembrane proteins for their signal transduction (Fujisawa, 2004). More specifically, Nrp2 is considered the specific receptor for Sema3F (Giger et al., 1998; Chen et al., 2000; Giger et al., 2000). To assess whether the neurons in the ventral tangential migration expressed Nrp2, we used a Nrp-2 mutant mouse line of which the Nrp-2 locus contains $\beta$-galactosidase reporter gene (Takashima et al., 2002). Immunostaining of the Nrp2 heterozygous mutants revealed that surface neurons in the telencephalon began expressing $\beta$-galactosidase by E11.5 (Fig. 3A- $A^{\prime \prime}$ ). Distribution of these cells was largely overlapped with lot cells, and some cells were actually found double positive for $\beta$-galactosidase and $\mathrm{mAb}$ lot1, although the immunoreactivity for $\mathrm{mAb}$ lot 1 was still weak to be fully detected at this stage (Fig. 3A). Actual expression of Nrp2 protein was also confirmed immunohisotochemically in lot cells at E11.5 (Fig. 3B- $B^{\prime \prime}$ ). Because $\mathrm{mAb}$ lot1 is a relatively late maker of the differentiation, lot cells adequately maturated in culture for $4 \mathrm{~d}$ after dissociation from the E11.5 neocortex and were subsequently double immunostained with mAb lot1 and antiNrp2 antibody (Fig. 3C- $C^{\prime \prime}$ ). This analysis showed that $\sim 80 \%$ of lot1-positive cells were immunopositive for Nrp2.

Additional analysis indicated that Nrp2 was indeed required for the repulsion of neurons by Sema3F. When Sema3Fexpressing cell aggregates were cocultured with telencephalic slices prepared from the Nrp2 homozygous knock-out embryos, the DiI-labeled cells lacking Nrp2 did not respond to Sema3F (Fig. 3D-F). The cell distribution demonstrated that the migration stream was not biased to either the distal or the proximal side of the aggregates, but directed ventrally (Fig. $3 G-J$ ). These results indicate that the repulsive signal of Sema3F is mediated by Nrp2 in these migrating neurons. Nrp2 heterozygous neurons appeared less sensitive to Sema3F compared with those in wild-type embryos, although the quantification did not reveal a statistical significance (Fig. $3 J$ ).

The culture of Nrp2 homozygous slices suggested that the initial phase of the ventrally directed migration was relatively independent of endogenous Sema3F/Nrp2 signaling, because the ventral migration displayed by the DiI-labeled cells was indistinguishable from that in wild-type telencephalons without exogenous guidance molecules (compare Figs. 2D, 3I). To further evaluate the intrinsic Sema3F signal in slices, we cocultured telencephalic slices prepared from Sema3F knock-out embryos with Sema3F-expressing cell aggregates (Fig. $3 K, L$ ). In this type of combination, only the exogenous source of Seama3F functions for the neuronal migration. The distribution of DiI-labeled cells was, however, indistinguishable from that in the wild-type slice that might contain intrinsic Sema3F (Fig. $3 M, N$ ). Thus, the initial ventral migration of neurons appeared not to depend on endogenous Sema3F. Although we could not directly compare the amounts of Sema3F from the endogenous and exogenous sources, the endogenous expression of Sema3F on this stage might not be sufficiently high to affect the migration.

\section{Sema3F is expressed in the mantle region of the GE}

We examined the expression of Sema3F by in situ hybridization. The ventral tangential migration is most prominent at E9.5E10.5, and from E11.5 onwards, many neurons terminate the migration and accumulate at the neocortex-GE boundary (Tomioka et al., 2000). The hybridization signals for Sema3F were undetectable at E10.5 (data not shown). At E11.5, Sema3F expression first emerged in the mantle zone of the lateral and medial GE (Fig. 4A,C,E). Because the ventricular zone was negative for the signals, differentiated neurons in the GE appeared to express the mRNA. The expression was weak rostrally (Fig. 4A), intensified caudally, and especially strong in the dorsal margin of the lateral GE, which was surrounding the future LOT position on which lot cells were about to settle (Fig. 4C,E). From E12.5 onwards, the Sema3F expression widened in parallel with the 

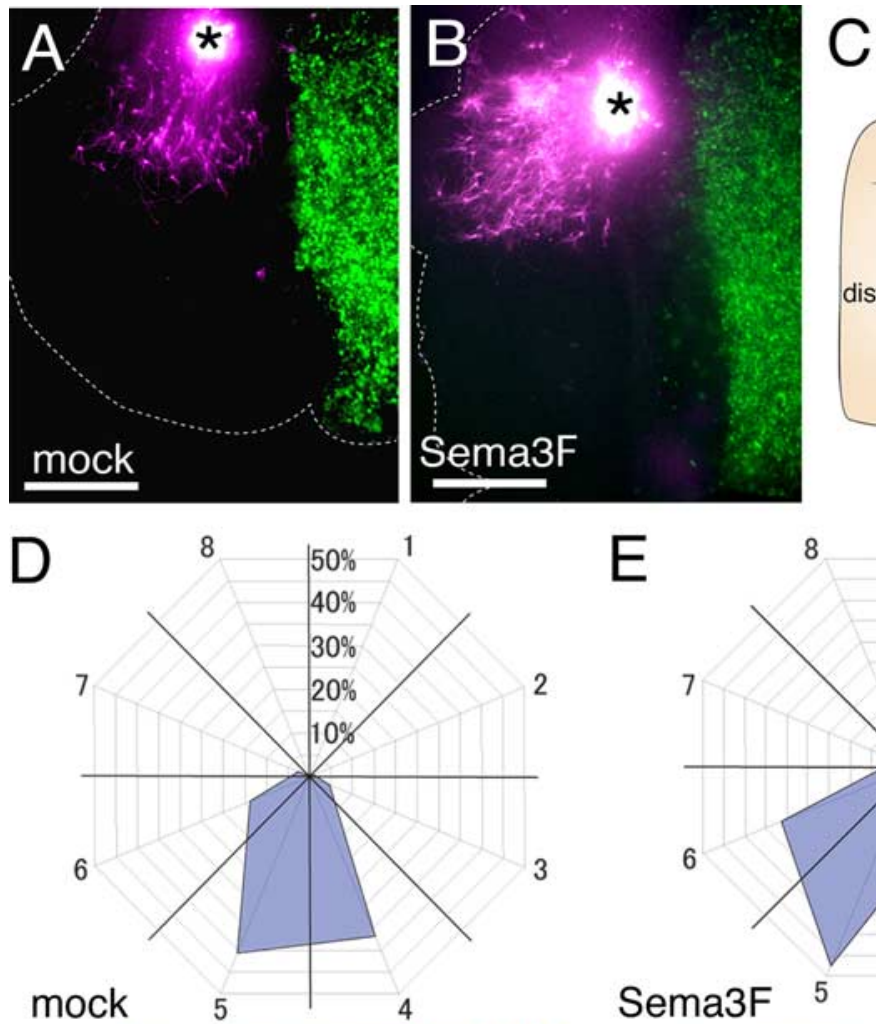

2

mock

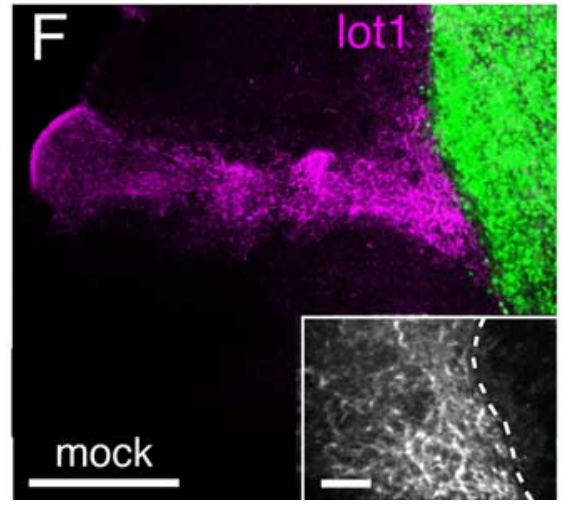

Sema3F
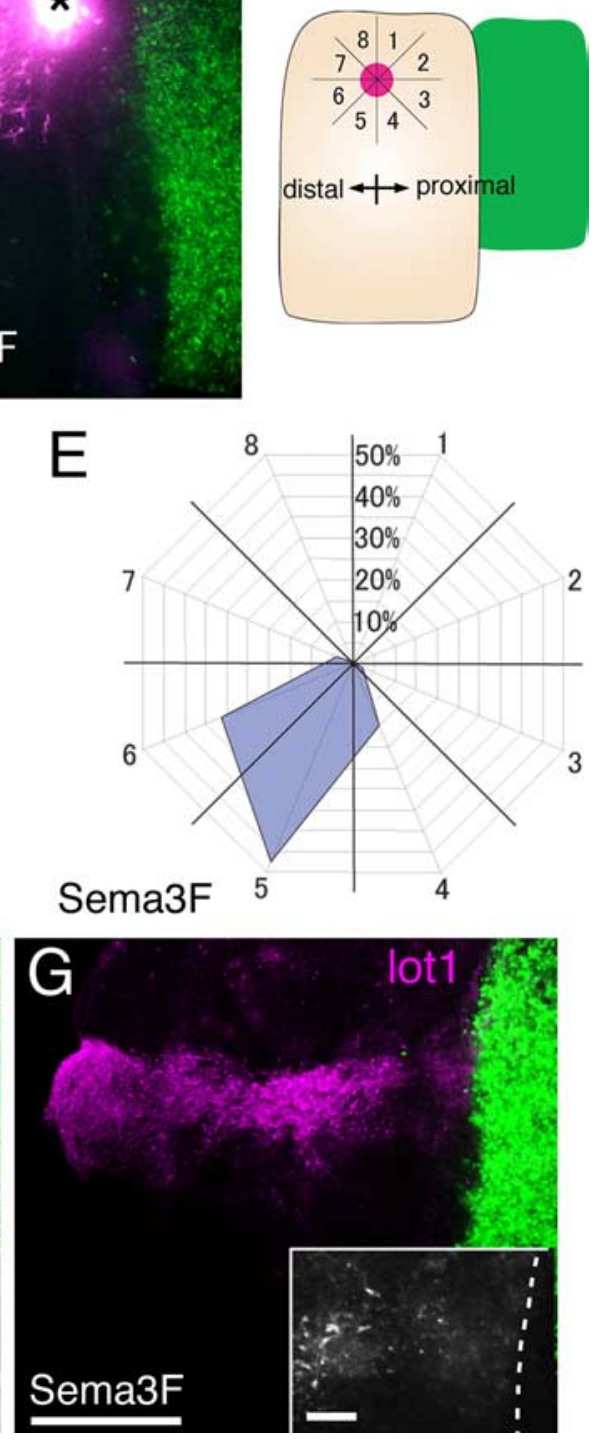

Figure 2. Repulsion of the ventral tangential migration stream by Sema3F. A, A slice cultured with a cell aggregate transfected with GFP cDNA alone (green). The aggregate does not influence the ventral tangential migration of Dil-labeled cells (magenta). $\boldsymbol{B}$, A slice cultured with a cell aggregate expressing Sema3F and GFP (green). The Dil-labeled cells (magenta) migrate toward the opposite side of the Sema3F-expressing aggregate. Asterisks indicate the Dil injection points. C, A schema to quantify the cell distribution. The slice was subdivided into eight sections with $45^{\circ}$ angled radial lines centered on the Dil-injection point (magenta dot), and the sections were numbered clockwise. The base line dividing sections 1 from 8 and 4 from 5 was carefully adjusted along the dorsoventral axis in the slice, so that sections $1-4$ are defined as the proximal area and sections $5-8$ are the distal area to the cell aggregate. The numbers of the Dil-labeled cells in each section were counted and represented as proportion on a radar graph. $\boldsymbol{D}$, A radar graph showing cell distribution in 69 slices cultured with control mock-transfected aggregates. Approximately equal proportions of the cells have migrated to sections 4 and 5 , indicating that the cells migrate simply ventrally. $\boldsymbol{E}$, A radar graph showing the cell distribution in 53 slices cultured with Sema3F-expressing aggregates. The majority of the cells have migrated to sections 5 and 6 , indicating that the cells are repelled by Sema3F. $F$, A slice cultured with GFP cDNA mock transfectants (green) and immunostained with $\mathrm{mAb}$ lot 1 (magenta). The lot cells on the right end of the array contact the aggregate of transfectants. G, A slice cultured with Sema3F and GFP-expressing transfectants (green) and immunostained with mAb lot 1 (magenta). The lot cells are sparse around the combination boundary with the transfectants. The insets in $\boldsymbol{F}$ and $\boldsymbol{G}$ are close-ups around the combination boundary (dotted line) with the transfectants, displaying only $\mathrm{mAb}$ lot 1 staining. Scale bars: $\boldsymbol{A}, \boldsymbol{B}, \boldsymbol{F}, \mathbf{G}, 500 \mu \mathrm{m}$; insets, $50 \mu \mathrm{m}$.

enlargement of the GE (Fig. $4 B, D, F$ ). The highest expression level was found in the area medial to the LOT position, around which differentiated GE neurons were packed densely (Fig. $4 D)$. At this stage, the Sema3F expression appeared in a line of neurons constituting the developing neocortical plate (Fig.
$4 D, F)$. Thus, Sema3F expression now firmly surrounded the presumptive LOT position populated with many lot cells waiting for the projecting LOT axons (Fig. $4 G, H$ ). On a more caudal level in which the LOT was no longer present, Sema3F was more diffusely expressed over the wide mantle region of the caudal GE (Fig. $4 F$ ). These expression patterns suggest that Sema3F can function to confine the neurons accumulating at the LOT position in the late migratory stage.

Ectopic spread of lot cells into deep layers in $\mathrm{Nrp} 2$ and Sema3F mutant embryos

To examine the role of Sema3F/Nrp2 signaling in vivo, we investigated the distribution of lot cells in Nrp2 and Sema3F mutant mice. Whole-mount immunostaining of the telencephalons with $\mathrm{mAb}$ lot1 allowed visualization of the overall distribution of lot cells. The surface distribution of lot cells in the homozygous mutants was indistinguishable from that in wild-type embryos; lot cells constructed a cellular array at the proper position, showing little invasion down into the ventral area across the neocortex-GE boundary (Fig. 5A-C). Therefore, the general migration and termination of the neurons seemed intact even when Sema3F/Nrp2 signaling was disrupted.

Once the three-dimensional distribution of lot cells was examined, however, we identified a difference between the wild-type and mutant embryos. Normally, lot cells were mostly confined to the surface of the telencephalon and only few penetrated into the medial depth toward the GE (Fig. 5D). In contrast, in Nrp2 and Sema3F homozygous mutant embryos, an increased number of lot cells spread over the deep medial region, although the majority of the cells were still located on the normal brain surface (Fig. $5 E, F$ ), and the total numbers of lot cells were not different between wild-type and the mutant embryos (Fig. 5H). This deeper dispersion of lot cells was marked only at the restricted rostrocaudal level, around which the strong LOT-surrounding expression of Sema3F was documented (Fig. 4D). On this middle level, about twice as many lot cells were ectopically distributed over the deep layers in the Nrp2 and Sema3F homozygotes compared with wild-type embryos (Fig. $5 G)$. On a more rostral level, lot cells were properly confined to the surface even in the mutants, whereas on a more caudal level, lot cells were rather broadly distributed over the deep layers even in wild-type embryos, obscuring a difference between the wild-type and homozygous mutant embryos.

Although there were some individual variations, the quanti- 

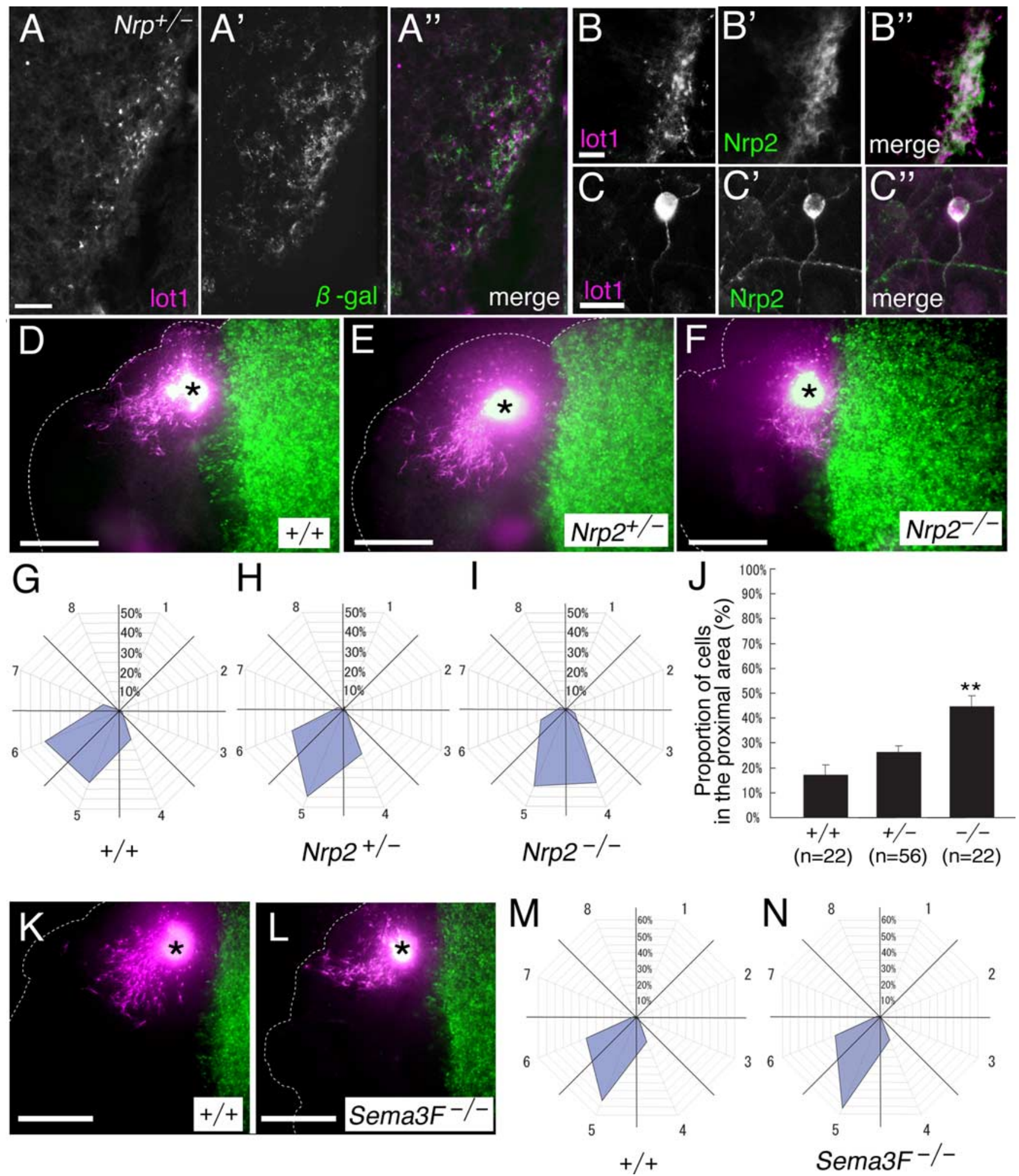

Figure 3. Neuropilin-2-dependent repulsion of the neurons by Sema3F. $A-A^{\prime \prime}$, Immunostaining of a coronal telencephalic section from an E11.5 Nrp 2 heterozygous mutant embryo in which the mutant allele contains $\beta$-galactosidase reporter gene. The mAb lot1 immunostaining $\left(\boldsymbol{A} ; \boldsymbol{A}^{\prime \prime}\right.$, magenta) substantially overlaps with anti- $\beta$-galactosidase staining $\left(\boldsymbol{A}^{\prime} ; \boldsymbol{A}^{\prime \prime}\right.$, green). $\boldsymbol{B}-\boldsymbol{B}^{\prime \prime}, A$ section of the E11.5 wild-type telencephalon double-immunostained with mAb lot $1\left(\boldsymbol{B} ; \boldsymbol{B}^{\prime \prime}\right.$, magenta) and anti-Nrp2 antibody $\left(\boldsymbol{B}^{\prime} ; \boldsymbol{B}^{\prime \prime}\right.$, green). Strong immunoreactivity to Npn2 protein is detected around lot cells. $\boldsymbol{C}-\boldsymbol{C}^{\prime \prime}$, Cultured cortical neurons immunostained with mAb lot1 $\left(\boldsymbol{C} ; \boldsymbol{C}^{\prime}\right.$, magenta) and anti-Nrp2 antibody $\left(\boldsymbol{C}^{\prime} ; \boldsymbol{C}^{\prime \prime}\right.$, green). The lot1-positive cell is immunopositive for anti-Nrp2 antibody. $\boldsymbol{D}-\boldsymbol{F}$, Coculture of the slices from E10.5 wild-type (D), Nrp2 heterozygous $(\boldsymbol{E})$, and Nrp2 homozygous $(\boldsymbol{F})$ mutant embryos with Sema3F-expressing aggregates (green). Asterisks indicate the Dil injection points. The Dil-labeled cells (magenta) in the Nrp2 homozygous mutant slice are unresponsive to Sema3F (F). G-I, Radar graphs showing the cell distribution in 22 wild-type (G), 56 Nrp2 heterozygous $(\boldsymbol{H})$, and $22 \mathrm{Nrp} 2$ homozygous $(\boldsymbol{I})$ slices. J, Effect of genotypes on the proportion of Dil-labeled cells in the proximal area (sections $1-4)$. Data are represented as mean \pm SEM calculated from the numbers of slices indicated by $n .{ }^{* *} p<0.001$ by Student's $t$ test compared with the value of wild-type slices. $\boldsymbol{K}, L$, Coculture of the slices from E10.5 wild-type $(\boldsymbol{K})$ and $S e m a 3 F$ homozygous ( $\boldsymbol{L}$ ) mutant siblings with Sema3F-expressing aggregates (green). Asterisks indicate the Dil injection points. The Dil-labeled cells (magenta) are similarly repelled in the two slices. $\boldsymbol{M}$, $\boldsymbol{N}$, Radar graphs showing the cell distribution in 20 wild-type $(\boldsymbol{M})$ and 18 Sema3F homozygous $(\boldsymbol{N})$ slices. Scale bars: $\boldsymbol{A}, 100 \mu \mathrm{m} ; \boldsymbol{B}, \boldsymbol{C}, 20 \mu \mathrm{m} ; \boldsymbol{D}-\boldsymbol{F}, \boldsymbol{K}, \boldsymbol{L}, 500 \mu \mathrm{m}$. 


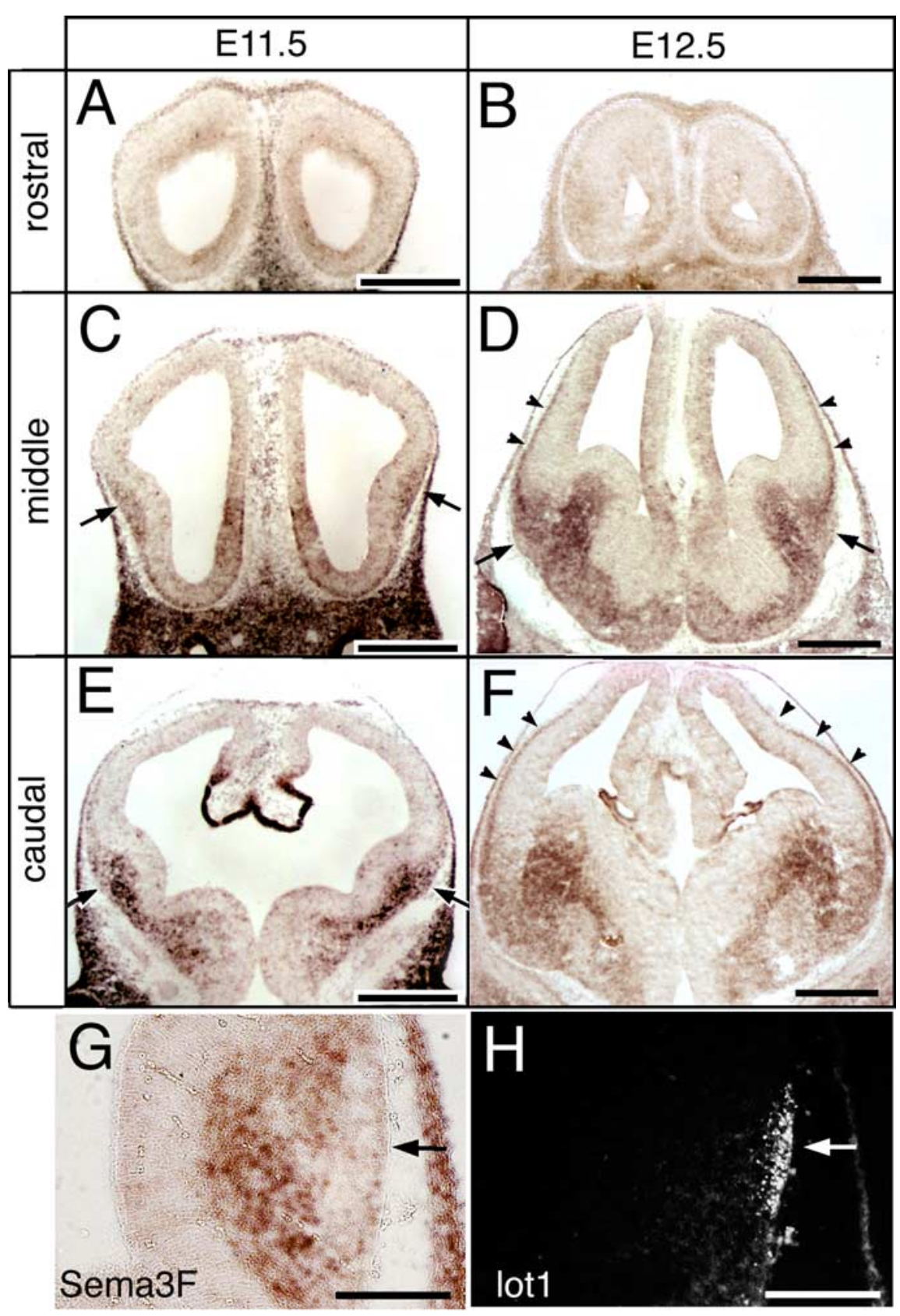

Figure 4. Expression of Sema3F in the developing telencephalon. $A-F$, In situ hybridization for Sema3F mRNA on coronal sections of E11.5 $(\boldsymbol{A}, \boldsymbol{C}, \boldsymbol{E})$ and E12.5 $(\boldsymbol{B}, \boldsymbol{D}, \boldsymbol{F})$ telencephalons at different rostrocaudal levels. Strong signals are detected in the mantle region of the lateral GE juxtaposed to the future $L O T$ position ( $(-\boldsymbol{E}$, arrows). At E12.5, the expression on the surface layer of the neocortex is also manifested $(\boldsymbol{D}, \boldsymbol{F}$, arrowheads). $\boldsymbol{G}, \boldsymbol{H}$, Complementary distribution of Sema3F mRNA (G) and lot cells $(\boldsymbol{H})$ on adjacent sections at E12.5. Arrows indicate the presumptive $L 0 T$ position populated with lot cells. Scale bars: $\boldsymbol{A}-\boldsymbol{F}, 500 \mu \mathrm{m} ; \boldsymbol{G}$, H, $200 \mu \mathrm{m}$.

tative analysis showed that Sema3F and Nrp2 mutants had a similar severity of ectopic dispersion of lot cells, suggesting that this ligand-receptor combination primarily regulates this positioning (Fig. 5G). Developmentally, the phenotypes were similarly obvious at E12.5 and E13.5. Thus, lot cells in the Sema3F and Nrp2 mutants seem to have strayed into the deep layers by the stage at which these neurons almost finish the ventral tangential migration and arrange along the future LOT position.

\section{Discussion}

From combinational culture experiments (Kawasaki et al., 2006), we previously proposed a model in which the telencephalon has a guidance signal with a dorsoventral gradient, which orients the early neuronal migration into a ventral direction (Fig. 6A). At the same time, the region ventral to the future LOT position repels the invading lot cells, which terminates the migration and aligns the neurons. This model explains why lot cells are directed ventrally in the initial stages and stop at the ventral boundary of the neocortex, but does not take into account why these cells stay on the surface of the telencephalon. The present study answered the question and refined the model with a new additional mechanism; Sema3F surrounding the LOT confines lot cells to the surface by its repulsive action (Fig. 6A).

Because of the late expression of the antigen, mAb lot 1 cannot detect lot cells until the postmigratory stage. Therefore, it is not completely clear which exact stage of the ventral tangential migration is regulated by Sema3F. However, we consider that this mechanism is predominantly operational around the final stage of the migration, when the neurons change their migration direction and accumulate on the neocortex-GE border, for the following reasons. First, the expression of Sema3F mRNA was first detected in the telencephalon at E11.5, slightly lagging behind the initiation of the ventral tangential migration. Second, the behavior of ventrally migrating cells in culture of Nrp2 or Sema3F homozygous mutant slices was indistinguishable from that in wild-type slices, suggesting that the initial phase of the ventral tangential migration is relatively independent of endogenous Sema3F/Nrp2 signaling. Although a later-born fraction could have to migrate toward the GE that has started expressing Sema3F, the endogenous Sema3F may be still insufficient in amount or locally constrained within the GE, and therefore could not exert a long-range effect on the ventrally directed migration. Finally, the ectopic penetration of lot cells into the deep brain was similarly significant at E12.5 and E13.5 in the mutant embryos, while the majority of neurons are terminating the ventrally directed migration and lining up the boundary. Together, the physiological function of Sema3F seems primarily devoted to preventing the deeper dispersion of the neurons in the final stage of ventral tangential migration. The subsequent expression of Sema3F in the neocortical plate after E12.5 may have some additional function to prevent a later migrating subset of neurons from invading the cortical plate, as suggested for guidance of GABAergic neurons in the dorsal tangential migration stream (Tamamaki et al., 2003) that occurs slightly later in development.

Although a significant number of lot cells penetrated the deep medial layers in Nrp2 and Sema3F mutant mice, the majority of these cells were still located on the surface. Although this type of 
variation can be explained by a stochastic mechanism, it is also possible that individual lot cells differently require Sema3F signals in their positioning. Indeed, we found that only $80 \%$ of lot 1 -positive neurons express Nrp2 in culture. Together with the previous report pointing out a molecular heterogeneity among lot cells (Sato et al., 1998), some of the lot cells may rely more heavily on a different mechanism that anchors these neurons to the surface. Interestingly, a recent study reports LOTsurrounding expression of Sema6A (Saha et al., 2007), a distant semaphorin family member that does not require Nrp2 for the action, which may have a similar role in positioning of lot cells Furthermore, it should be pointed out that many of the tangential migration routes are actually positioned on the brain surface, and that the attractive force from the pia matter wrapping the brain outer surface has been postulated in recent years (Reiss et al., 2002; Zhu et al., 2002; Borrell and Marin, 2006; Paredes et al., 2006).

Lot cells still constructed a definite cellular array even when Sema3F/Nrp2 signaling was disrupted. Therefore, other signaling systems are likely to be involved in the termination of migration at the ventral edge of the neocortex. In our previous study, we directly combined the neocortical area with various domains of the GE and found that the entire area of the GE is capable of excluding the neuronal migration (Kawasaki et al., 2006). This repulsion does not act over a long-range; the excluded neurons are lined up in the immediate vicinity alongside the combination interface. Thus, a short-range repulsive guidance molecule could be an excellent candidate for creating this ventral barrier.

Recently, two other neuronal popula-

tions in addition to lot cells have been described to make ventral tangential migration (Fig. 6B). One is a fraction of Reelin-positive Cajal-Retzius cells that are generated from the cortical hem, the dorsomedial edge of the telencephalon and tangentially spread over the telencephalon (TakiguchiHayashi et al., 2004; Yoshida et al., 2006). This migration route overlaps substantially with that of lot cells, although the two populations are basically separable from several aspects. For example, lot cells are generated from the neuroepithelial cells of the neocortical proper (Tomioka et al., 2000). Furthermore, lot cells do not express Reelin, although some of them express calretinin, another marker of Cajal-Retzius cells (Sato et al., 1998). The other population in the ventral tangential migration is olfactory cortex neurons described by Nomura et al. (2006). These neurons follow a migration stream very similar to lot cells, and even stop and align on the neocortex-GE boundary. However, their migration slightly precedes that of lot cells, and the mechanism that terminates the migration seems substantially different from that of lot cells. Indeed, these neurons recognize the neocortex-GE boundary, relying on the neocortex-specific expression of Pax6 transcription factor, and repelled by ephrin-A5, a membrane-bound guidance molecule (Nomura et al., 2006). However, neither Pax6 nor ephrin-A5 seems critical for the termination of lot cell migration (Hirata et al., 2002; Nomura et al., 2006). In conclusion, heterogeneous neuronal populations migrate in a ventral tangential direction, which sum up into the most prominent migration stream in the earliest stage of the developing telencephalon. These populations may share the same guidance mechanism for mainstreaming, but also be controlled by different mechanisms. Especially, for termination of the migration, it is reasonable that each population relies on a different guidance mechanism, because adequate settlement is a critical requisite for each population to fulfill the destined function.

It is interesting to explore the developmental consequences of disturbances of the ventral tangential migration in Sema3F and Nrp2 mutant mice. Because the alignment of lot cells is required for the subsequent projection of LOT axons (Sato et al., 1998), the trajectory of these axons deserves further study. Although this projection has so far been reported to be normal in Nrp2 mutant mice (Chen et al., 2000), more detailed analysis may lead to a 

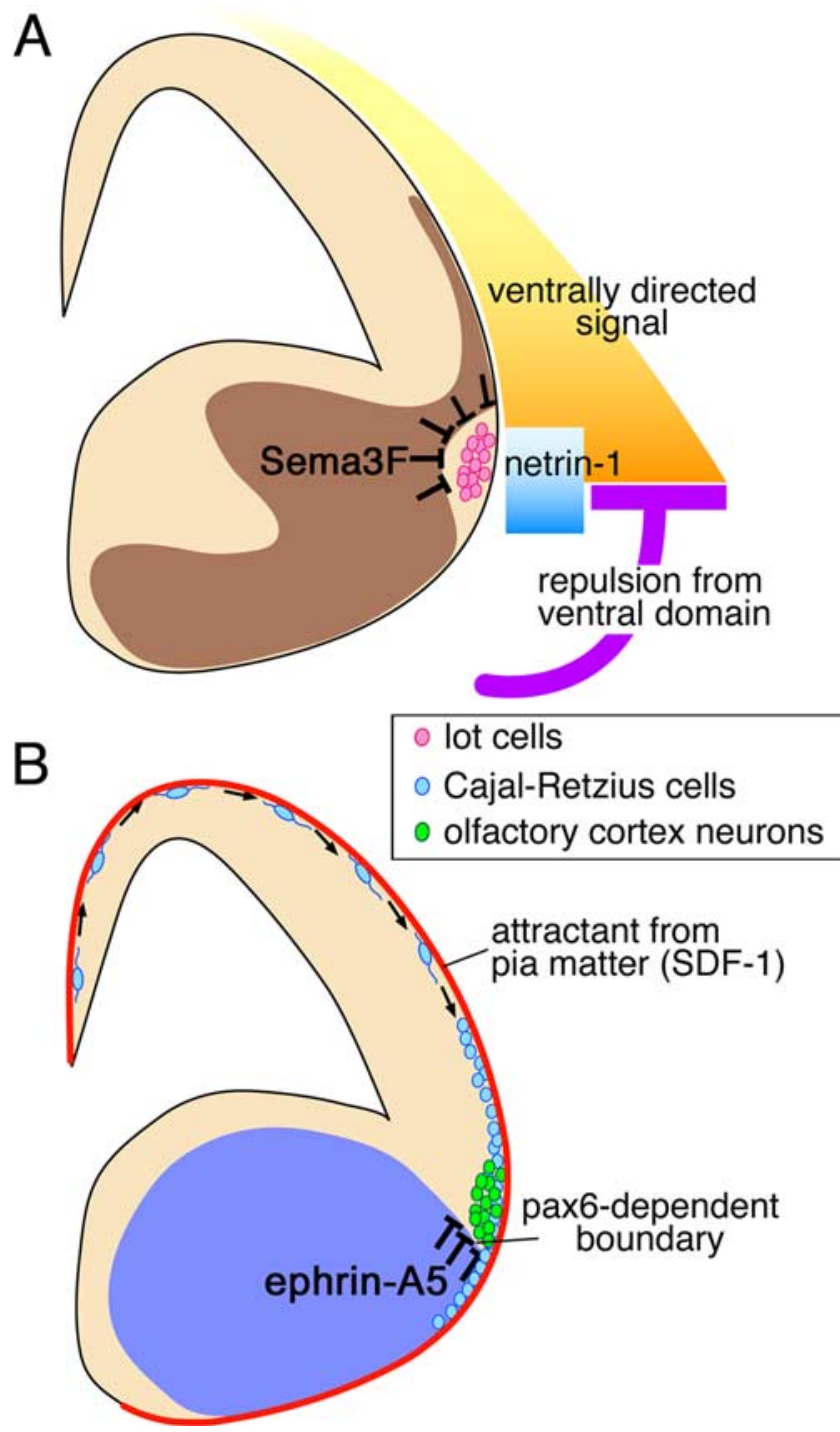

Figure 6. Guidance mechanisms for the ventral tangential migration. $A$, Mechanisms proposed for the control of migration of lot cells (pink). The neocortex has the dorsoventrally graded signal (yellow) that ventrally orients the initial stage of the migration. The ventral telencephalon has a repulsive mechanism (purple) that prevents lot cells from invading the ventral area, which creates the major force to align lot cells along the neocortex-GE boundary. Netrin-1 secreted from the ventral brain (blue) ventrally attracts lot cells locally around the neocortex-GE boundary (Kawasaki et al., 2006). Furthermore, the present study provides evidence that Sema3F in the deep domain (dark brown) pushes lot cells on the surface by its repulsive action. $\boldsymbol{B}$, Mechanisms proposed for other neurons in the ventral tangential migration stream. A population of (ajal-Retzius cells (light blue) that are generated from the dorsomedial end of the telencephalon, the cortical hem, spread ventrally during early development. Surface confinement of these neurons is achieved by stromal-cell-derived factor (SDF)-1 secreted from the pia matter wrapping the whole brain (red line) (Borrell and Marin, 2006; Paredes et al., 2006). Olfactory cortexneurons (green) migrate ventrally and align at the neocortex-GEboundary similarly to lot cells. Termination of the migration is regulated by ephrin- $\mathrm{A5}$ (blue), of which expression is regulated by the Pax6-dependent neocortex-GE boundary (Nomura et al., 2006).

deformity, considering the partial ectopic dispersion of lot cells in the mutants. Last, the basic design of the ventral tangential migration is to deliver the early-generated neurons to their destinations. This pioneering work will become even more important, given the fact that many of the early-generated neurons play an indispensable role in molding the subsequent developmental processes.

\section{References}

Anderson SA, Eisenstat DD, Shi L, Rubenstein JL (1997) Interneuron migration from basal forebrain to neocortex: dependence on Dlx genes. Science 278:474-476.

Borrell V, Marin O (2006) Meninges control tangential migration of hemderived Cajal-Retzius cells via CXCL12/CXCR4 signaling. Nat Neurosci 9:1284-1293.

Chen H, Bagri A, Zupicich JA, Zou Y, Stoeckli E, Pleasure SJ, Lowenstein DH, Skarnes WC, Chedotal A, Tessier-Lavigne M (2000) Neuropilin-2 regulates the development of selective cranial and sensory nerves and hippocampal mossy fiber projections. Neuron 25:43-56.

Fan CM, Porter JA, Chiang C, Chang DT, Beachy PA, Tessier-Lavigne M (1995) Long-range sclerotome induction by sonic hedgehog: direct role of the amino-terminal cleavage product and modulation by the cyclic AMP signaling pathway. Cell 81:457-465.

Fujisawa H (2004) Discovery of semaphorin receptors, neuropilin and plexin, and their functions in neural development. J Neurobiol 59:24-33.

Giger RJ, Urquhart ER, Gillespie SK, Levengood DV, Ginty DD, Kolodkin AL (1998) Neuropilin-2 is a receptor for semaphorin IV: insight into the structural basis of receptor function and specificity. Neuron 21:1079-1092.

Giger RJ, Cloutier JF, Sahay A, Prinjha RK, Levengood DV, Moore SE, Pickering S, Simmons D, Rastan S Walsh FS, Kolodkin AL, Ginty DD, Geppert M (2000) Neuropilin-2 is required in vivo for selective axon guidance responses to secreted semaphorins. Neuron 25:29-41.

Hirata T, Nomura T, Takagi Y, Sato Y, Tomioka N, Fujisawa H, Osumi N (2002) Mosaic development of the olfactory cortex with Pax6-dependent and -independent components. Dev Brain Res 136:17-26.

Kawasaki T, Ito K, Hirata T (2006) Netrin 1 regulates ventral tangential migration of guidepost neurons in the lateral olfactory tract. Development 133:845-853.

Kitsukawa T, Shimizu M, Sanbo M, Hirata T, Taniguchi M, Bekku Y, Yagi T, Fujisawa H (1997) Neuropilin-semaphorin III/D-mediated chemorepulsive signals play a crucial role in peripheral nerve projection in mice. Neuron 19:995-1005.

Kruger RP, Aurandt J, Guan KL (2005) Semaphorins command cells to move. Nat Rev Mol Cell Biol 6:789-800.

Luo Y, Raible D, Raper JA (1993) Collapsin: a protein in brain that induces the collapse and paralysis of neuronal growth cones. Cell 75:217-227.

Marin O, Rubenstein JL (2003) Cell migration in the forebrain. Annu Rev Neurosci 26:441-483.

Marin O, Yaron A, Bagri A, Tessier-Lavigne M, Rubenstein JL (2001) Sorting of striatal and cortical interneurons regulated by semaphorinneuropilin interactions. Science 293:872-875.

Nadarajah B, Parnavelas JG (2002) Modes of neuronal migration in the developing cerebral cortex. Nat Rev Neurosci 3:423-432.

Nomura T, Holmberg J, Frisen J, Osumi N (2006) Pax6-dependent boundary defines alignment of migrating olfactory cortex neurons via the repulsive activity of ephrin A5. Development 133:1335-2345.

Paredes MF, Li G, Berger O, Baraban SC, Pleasure SJ (2006) Stromalderived factor-1 (CXCL12) regulates laminar position of Cajal-Retzius cells in normal and dysplastic brains. J Neurosci 26:9404-9412.

Pasterkamp RJ, Kolodkin AL (2003) Semaphorin junction: making tracks toward neural connectivity. Curr Opin Neurobiol 13:79-89.

Raper JA (2000) Semaphorins and their receptors in vertebrates and invertebrates. Curr Opin Neurobiol 10:88-94.

Reiss K, Mentlein R, Sievers J, Hartmann D (2002) Stromal cell-derived factor 1 is secreted by meningeal cells and acts as chemotactic factor on neuronal stem cells of the cerebellar external granular layer. Neuroscience 115:295-305.

Roche J, Boldog F, Robinson M, Robinson L, Varella-Garcia M, Swanton M, Waggoner B, Fishel R, Franklin W, Gemmill R, Drabkin H (1996) Distinct 3 p21.3 deletions in lung cancer and identification of a new human semaphorin. Oncogene 12:1289-1297.

Saha B, Hari P, Huilgol D, Tole S (2007) Dual role for LIM-homeodomain gene Lhx2 in the formation of the lateral olfactory tract. J Neurosci 27:2290-2297.

Sato Y, Hirata T, Ogawa M, Fujisawa H (1998) Requirement for earlygenerated neurons recognized by monoclonal antibody lot 1 in the formation of lateral olfactory tract. J Neurosci 18:7800-7810.

Schaeren-Wiemers N, Gerfin-Moser A (1993) A single protocol to detect 
transcripts of various types and expression levels in neural tissue and cultured cells: in situ hybridization using digoxigenin-labelled cRNA probes. Histochemistry 100:431-440.

Sekido Y, Bader S, Latif F, Chen JY, Duh FM, Wei MH, Albanesi JP, Lee CC, Lerman MI, Minna JD (1996) Human semaphorins A(V) and IV reside in the 3 p21.3 small cell lung cancer deletion region and demonstrate distinct expression patterns. Proc Natl Acad Sci USA 93:4120-4125.

Takashima S, Kitakaze M, Asakura M, Asanuma H, Sanada S, Tashiro F, Niwa H, Miyazaki Ji J, Hirota S, Kitamura Y, Kistukawa T, Fujisawa H, Klagsbrurn M, Hori M (2002) Targeting of both mouse neuropilin-1 and neuropilin-2 genes severely impairs developmental yolk sac and embryonic angiogenesis. Proc Natl Acad Sci USA 99:3657-3662.

Takiguchi-Hayashi K, Sekiguchi M, Ashigaki S, Takamatsu M, Hasegawa H, Suzuki-Migishima R, Yokoyama M, Nakanishi S, Tanabe Y (2004) Generation of reelin-positive marginal zone cells from the caudomedial wall of telencephalic vesicles. J Neurosci 24:2286-2295.

Tamamaki N, Fujimori KE, Takauji R (1997) Origin and route of tangen- tially migrating neurons in the developing neocortical intermediate zone. J Neurosci 17:8313-8323.

Tamamaki N, Fujimori K, Nojyo Y, Kaneko T, Takauji R (2003) Evidence that sema $3 \mathrm{~A}$ and sema3F regulate the migration of GABAergic neurons in the developing neocortex. J Comp Neurol 455:238-248.

Tomioka N, Osumi N, Sato Y, Inoue T, Nakamura S, Fujisawa H, Hirata T (2000) Neocortical origin and tangential migration of guidepost neurons in the lateral olfactory tract. J Neurosci 20:5802-5812.

Xiang RH, Hensel CH, Garcia DK, Carlson HC, Kok K, Daly MC, Kerbacher K, van den Berg A, Veldhuis P, Buys CH, Naylor SL (1996) Isolation of the human semaphorin III/F gene (SEMA3F) at chromosome 3p21, a region deleted in lung cancer. Genomics 32:39-48.

Yoshida M, Assimacopoulos S, Jones KR, Grove EA (2006) Massive loss of Cajal-Retzius cells does not disrupt neocortical layer order. Development 133:537-545.

Zhu Y, Yu T, Zhang XC, Nagasawa T, Wu JY, Rao Y (2002) Role of the chemokine SDF-1 as the meningeal attractant for embryonic cerebellar neurons. Nat Neurosci 5:719-720. 